\title{
Social Characteristics and their Importance in Reducing Inequalities in Health in the Armed Forces
}

\author{
Maj DA Ross \\ MSc, MBBS,DCCH,RAMC \\ Specialist Registrar in Public Health Medicine
}

Surgeon General's Department, Main Building, Whitehall, London SWIA 2HW

Mr TC Clayton

Medical Statistics Unit, London School of Hygiene and Tropical Medicine, Keppel Street, London WCIE 7HT

\section{SUMMARY:}

Objectives: To investigate whether there was a difference in social characteristics in different garrison towns of the

British Forces Germany and to ascertain whether the health visitor workload was different in these towns.

Design: Self completed questionnaires administered to mothers by health visitors on first contact after delivery of their baby, and prospective follow up by health visitors recording subsequent contacts for the first three months after birth.

Setting: 97 mothers based in Bruggen, Fallingbostel and Rheindahlen who had just delivered their new-born baby. Results: Response rates for Bruggen, Fallingbostel and Rheindahlen were $54.8 \%, 70.2 \%$ and $69.9 \%$ respectively. There was a significant difference between parents in Fallingbostel and Rheindahlen with higher levels of maternal smoking during pregnancy $(p=0.04)$, more fathers aged under 25 years $(p=0.004)$, lower paternal military rank $(p=0.003)$, and increased paternal absence of more than one month during the pregnancy $(p=0.001)$ in Fallingbostel. The characteristics in Bruggen were similar to those in Rheindahlen.

The workload of the health visitors, was significantly increased in Fallingbostel in comparison to Rheindahlen $(\mathrm{p}=\mathbf{0 . 0 0 3})$.

Conclusion: The use of social characteristics as an assessment of need would allow appropriate targeted healttin promotion and education resulting in a reduction in the inequalities of health in the Armed Forces.

\section{Introduction}

The British Forces Germany (BFG) population at the time of this study was approximately 74,000 with a paediatric population of 19,900 , with $42 \%$ of children being under the age of 5 years, and the majority of females of child bearing age. In a three month period there can be a $30 \%$ turnover in population. The population is spread over a geographical area only a little smaller than the size of Scotland.

Although there has always been a good infra-structure for welfare support in place, studies in the UK have shown that Army dependants are unwilling to seek help from official sources (1). There is therefore a requirement for such sources to be pro-active in BFG, to counter the disadvantages, such as lack of extended family support, for mothers and young children who may be "isolated."

The effects of growing up in a Service community are well documented in several studies, and often there may be problems related to social and environmental damage that are most commonly seen in communities in underprivileged inner-city areas, where there are low levels of parenting skills and inadequate provision of preventive health care $(1,2)$. The commonest problems in this type of population include sudden infant death syndrome (SIDS), child maltreatment, accidents, prematurity, poisoning, clinic default, language delay, immunisation default, and behavioural problems $(2,3)$.
The UK Registrar General's classification of social clase (4) is constructed by grouping similar occupations into ranks, with the middle rank of skilled workers furthe subdivided into manual and non manual. Strictly speaking, members of Her Majesty's Forces do not belong to a social class. However, if one extrapolates an individual's trades and skills into the recognised social class groups one would see a great variation both within units and in comparison with other units. Alternatively one could postulate that military rank may equate with particular social class groups (5). There is now convincing evidence that health status is related to social class with a growing inequality between those in the lower social classes and those in the higher $(6,7)$. The link between health and wealth can no longer be ignored.

Health promotion is recognised as being a major way to achieve the ultimate aim relating to children in relation to the "Health of the Nation", which is to ensure that all children achieve the best level of health, which includes physical, social and mental well being, so that they reach adulthood with their health uncompromised (8). Health promotion includes not only education and prevention, but also health protection (9). Health visitors are ideally suited for this role of health promotion, and have been shown to be effective in reducing accident rates in children by home visiting (10). In addition they provide the link for families to other services and are skilled at networking and forming 
healthy alliances with other statutory and voluntary organisations (11).

A recent study suggested that there was a considerable variation in maternal age with a corresponding difference in smoking and breast feeding rates between the different garrisons in BFG, and the Army and Royal Air Force bases (12). Based on this evidence it is reasonable to assume that health visitors in the garrisons where mothers are youngest, smoking rates highest and breast feeding lowest will be least able to tackle the problems without increased support. What is not clear is whether the amount of extra work generated in certain garrisons could be predicted from the social characteristics of the individual garrison population and this study examined that issue.

\section{Method}

The study was designed to gather information on the maternal and paternal social characteristics in BFG, to discover whether there was a difference between garrisons and to assess the workload of health visitors in terms of time spent with new-born babies.

In the first instance a questionnaire was designed, using questions validated in previous studies, and piloted on the mothers of 59 consecutive deliveries on the maternity unit at the British Military Hospital in Rinteln during October 1995. Following the pilot minor amendments were made to the questionnaire design in consultation with the Director of Health Visitors and the team leaders of the proposed garrisons in which the study was to be conducted. Three garrisons, Bruggen (RAF), Fallingbostel and Rheindahlen were selected for the main study based on the previously identified differences between these towns (12).
At first contact with all mothers of new-born babies, the mother was given a questionnaire to complete, by the 3 health visitor, between 1 January to 30 June 1996. The questionnaire was designed to gether general ${ }_{\Omega}^{\Phi}$ epidemiological data (birth weight, gestational age at birth, $\Omega$ parent's age etc.), socio-economic data (father's rank. education, employment, housing etc.) and data on partents'? habits (smoking, alcohol etc.). The questionnaires were $\Rightarrow$ treated as confidential, but each subject was allocated $a^{\rho ?}$ letter and number, so that the health visitor could recognise? them. At the next visit the health visitor would go through $\frac{\overline{\bar{N}}}{\mathrm{n}}$ any problems that the mother had had in completing the questionnaire, prior to returning it to the researcher.

After each initial contact the health visitor then made aw separate record of all further contacts with that family for $\overrightarrow{0}$ the next three months, recording details of contact andtime spent with the client. Numbers of births are recordedw centrally for each garrison on a monthly basis at The? Health Alliance Complex in Wegberg and these data weres collected to assess the response rate for each garrison. Similarly the number of health visitors working in the $\vec{f}$ garrisons during the study period was ascertained.

Categorical variables were compared between Fallingbostel and Rheindahlen using a Chi squared-test' except for those variables containing categories with smallo numbers where Fisher's exact test was used. The Wilcoxgnrank sum test was used to compare the workload of heathic

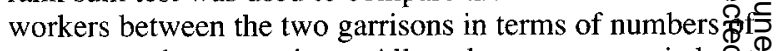
contacts and contact time. All analyses were carried oft using the STATA statistical package.

Table 1

Comparison of Characteristics between Bruggen, Fallingbostel and Rheindahlen Garrisons for Categorical Variables

\begin{tabular}{|c|c|c|c|c|c|}
\hline Characteristic & Category & $\begin{array}{c}\text { Bruggen } \\
(n=23)\end{array}$ & $\begin{array}{c}\text { Fallingbostel } \\
(\mathrm{n}-33)\end{array}$ & $\begin{array}{c}\text { Rheindahlen } \\
(n=39)\end{array}$ & P - Value* \\
\hline Maternal Age & $\begin{array}{l}<25 \\
25+\end{array}$ & $\begin{array}{l}4(17 \%) \\
19(83 \%)\end{array}$ & $\begin{array}{l}14(42 \%) \\
19(58 \%)\end{array}$ & $\begin{array}{l}12(31 \%) \\
27(69 \%)\end{array}$ & $0 . \overline{30}$ \\
\hline $\begin{array}{c}\text { Maternal } \\
\text { Smoking** }\end{array}$ & $\begin{array}{l}\text { Yes } \\
\text { No }\end{array}$ & $\begin{array}{c}2(9 \%) \\
21(91 \%)\end{array}$ & $\begin{array}{l}10(30 \%) \\
23(70 \%)\end{array}$ & $\begin{array}{r}4(10 \%) \\
35(90 \%)\end{array}$ & 0.04 \\
\hline Paternal Age & $\begin{array}{l}<25 \\
25+\end{array}$ & $\begin{array}{r}3(13 \%) \\
20(87 \%)\end{array}$ & $\begin{array}{l}13(39 \%) \\
20(61 \%)\end{array}$ & $\begin{array}{r}4(10 \%) \\
35(90 \%)\end{array}$ & $0 . \overline{004}$ \\
\hline $\begin{array}{c}\text { Paternal } \\
\text { Smoking** }\end{array}$ & $\begin{array}{l}\text { Yes } \\
\text { No }\end{array}$ & $\begin{array}{c}1(4 \%) \\
22(96 \%)\end{array}$ & $\begin{array}{r}9(27 \%) \\
24(73 \%)\end{array}$ & $\begin{array}{r}8(39 \%) \\
31(61 \%)\end{array}$ & $\overline{0.50}$ \\
\hline $\begin{array}{l}\text { Paternal } \\
\text { Rank }\end{array}$ & $\begin{array}{c}\text { Pte- SSgt } \\
\text { WO2+ }\end{array}$ & $\begin{array}{r}18(78 \%) \\
5(22 \%)\end{array}$ & $\begin{array}{c}30(91 \%) \\
3(9 \%)\end{array}$ & $\begin{array}{l}23(59 \%) \\
16(41 \%)\end{array}$ & 0.003 \\
\hline $\begin{array}{l}\text { Paternal } \\
\text { Absence } \\
\text { (during } \\
\text { pregnancy) }\end{array}$ & $\begin{array}{l}<1 \text { Month } \\
1 \text { Month+ }\end{array}$ & $\begin{array}{l}18(78 \%) \\
5(22 \%)\end{array}$ & $\begin{array}{l}10(30 \%) \\
23(70 \%)\end{array}$ & $\begin{array}{l}27(69 \%) \\
12(31 \%)\end{array}$ & 0.001 \\
\hline $\begin{array}{l}\text { Method of } \\
\text { Feeding }\end{array}$ & $\begin{array}{l}\text { Breast } \\
\text { Bottle* }\end{array}$ & $\begin{array}{l}12(52 \%) \\
11(48 \%)\end{array}$ & $\begin{array}{l}15(45 \%) \\
18(55 \%)\end{array}$ & $\begin{array}{l}20(51 \%) \\
19(49 \%)\end{array}$ & 0.62 \\
\hline
\end{tabular}

* Refers to a statistical comparison between Fallingbostel and Rheindahlen for categorical variables

** Refers to smoking during pregnancy

*** Includes mothers breast feeding and bottle feeding 


\section{Results}

Population Size: Bruggen (6297) and Fallingbostel (5093) were of similar size but Rheindahlen $(12,639)$ was approximately twice the size of both Bruggen and Fallingbostel.

Response Rate: The proportion of completed questionnaires were for Bruggen $(54.8 \%, \quad \mathrm{n}=23)$, Fallingbostel $(70.2 \%, \mathrm{n}=33)$ and Rheindahlen $(69.9 \%$, $\mathrm{n}=39$ ) but Bruggen only participated in the study for the first three months due to a change in staff amongst the health visitors.

Comparison of Characteristics between Bruggen, Fallingbostel and Rheindahlen for Cetegorical Variables: Table 1 shows the results when comparing maternal age, maternal smoking, paternal age, paternal smoking, paternal rank, paternal absence during pregnancy and method of feeding. Figures 1 and 2 show the maternal and paternal age distributions for each of the garrisons respectively. Figure 3 makes a comparison of the paternal smoking rates by age for each of the garrisons. Figure 4 demonstrates the frequency distribution of paternal absence during the confinement period for more than one month in the studied garrisons.

Table 1 also shows a statistical comparison between Fallingbostel and Rheindahlen, as they participated for the full six months of the study. It demonstrates that there is a significant difference between Fallingbostel and Rheindahlen for certain characteristics, with there being higher levels of maternal smoking, lower paternal age, lower paternal rank and increased paternal absence during pregnancy in Fallingbostel compared to Rheindahlen.

\section{Health Visitor Workload in the First Three Months After} Birth, with New Mothers: During the study period there was no fluctuations in the numbers of health visitors employed in Bruggen (2.5), Fallingbostel (3.0) and Rheindahlen (2.5); one health visitor working for an equal amount of time in both Bruggen and Rheindahlen.

When considering health visitor contacts only Fallingbostel and Rheindahlen provided sufficient data at the end of the study, with response rates (based on those who had answered the questionnaire) of $54.6 \%$ and $69.2 \%$ respectively. Both garrisons demonstrated common reasons for contact and these included primary visit, routine clinic attendance, weight measurement, immunisation, feeding problems, dietary advice, postnatal depression and general discussion. Table 2 demonstrates that there was an increased load per individual mother for the health visitors in Fallingbostel. Table 3 compares the time spent on each individual visit and demonstrates that the health visitors in Rheindahlen spent an average of two minutes longer on each visit.

\section{Discussion}

One of the major problems with this study and studies of similar design is the response rate and the potential for bias from non responders. Factors which need to be taken into account that limited the response rate were the mobility of
Table 2

Health Visitor Contact with Mothers in the First Three Months after Birth

\begin{tabular}{|c|c|c|c|c|}
\hline & & $\begin{array}{c}\text { Fallingbostel } \\
(\mathbf{n = 1 8})^{*}\end{array}$ & $\begin{array}{c}\text { Rheindahlen } \\
(\mathbf{n = 2 7})\end{array}$ & P - Value \\
\hline $\begin{array}{c}\text { Number of } \\
\text { Contacts }\end{array}$ & $\begin{array}{c}\text { Median } \\
\text { (IQR) }\end{array}$ & $\begin{array}{c}9 \\
(8-10)\end{array}$ & $(6-8)$ & 0.003 \\
\hline $\begin{array}{c}\text { Total } \\
\text { Contact Time } \\
\text { (minutes): }\end{array}$ & & & & \\
Actual & $\begin{array}{c}\text { Median } \\
\text { (IQR) }\end{array}$ & 172.5 & 140 & 0.11 \\
Weighted** & $\begin{array}{c}\text { Median } \\
\text { (IQR) }\end{array}$ & $\begin{array}{c}130-205) \\
(175-205)\end{array}$ & $\begin{array}{c}1130-160) \\
140\end{array}$ & 0.037 \\
\hline
\end{tabular}

* The number of mothers in Fallingbostel with information regarding "contact time" was 17

** Two mothers spent one of the three months in the UK following the birth. Their contact times were averaged up accordingly.

IQR Inter Quartile Range

Table 3

Comparison of Mean Time Spent per Visit

\begin{tabular}{|l|c|c|}
\hline & Fallingbostel & Rheindahlen \\
\hline Mean Time Spent (mins) & 171.5 & 152.0 \\
Mean Number of Contacts & 9.06 & 7.26 \\
Mean Time Spent per Visit & $\mathbf{1 8 . 9}$ mins & $\mathbf{2 0 . 9}$ mins \\
\hline
\end{tabular}

the population studied and the fact that the study relied oo the co-operation of health visitors to act as unpaid researchers. Statistical advice prior to the study ha\$ suggested that a sample size of 30 in each garrison woul provide a basis for reasonable conclusions to be drawn. IIs view of the study design the response rates for Fallingbostel and Rheindahlen were satisfactory but those of Bruggen less so. The problem of non response did not appear to lie with the subjects themselves, as verified by the pilot study but was due to non administration of the questionnaire by the health visitors due to pressures of work etc. However, much of the data collected in Miller's study (12) was replicated in this study suggesting that the data collected here were reliable. At the end of the study feedback from the health visitors that were currently in post in Bruggen suggested that the results that were presented relating to the Bruggen populace were consistent with their current client population.

The results support the hypothesis that there are different social characteristics between individual garrison towns in BFG and to some extent a difference between the RAF and the Army. It is well recognised that social status (e.g. manual social class) and associated habits (e.g. parental smoking) not only have a higher morbidity for the individual but also his or her offspring, particularly from respiratory illness (13). Furthermore the risk for children is a cumulative one and lifetime socio-economic circumstances are directly related to health inequality, with children born in social class V living for seven years less than those born into social class I families in Britain. 


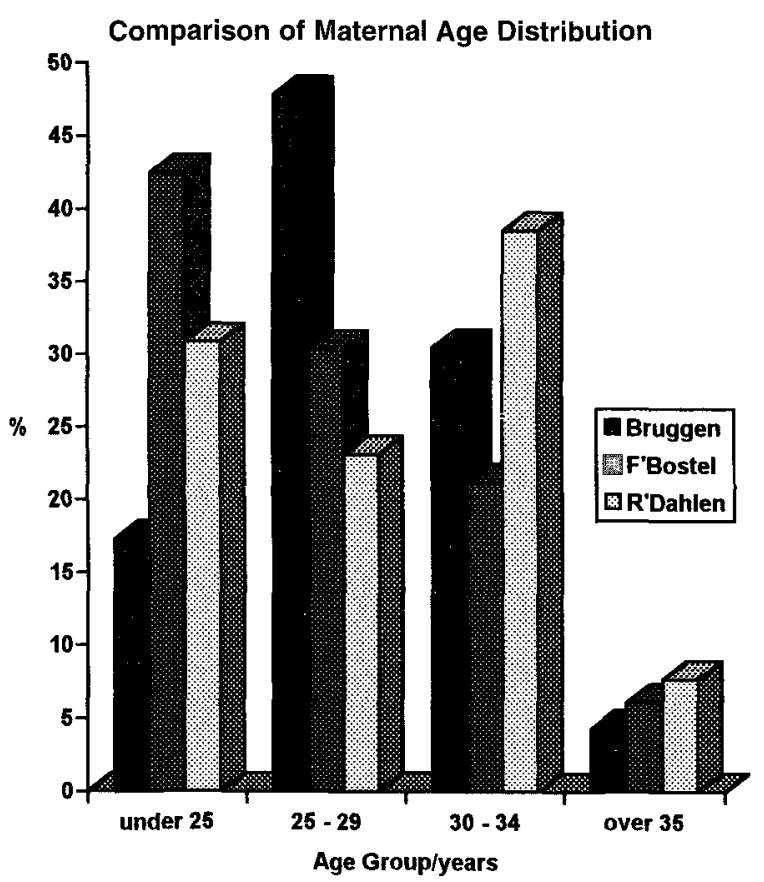

Fig 1. Comparison of Maternal Age Distribution in Bruggen, Fallingbostel and Rheindahlen of Mothers of New-born Babies, January - June 1996.

Paternal Smoking Distribution

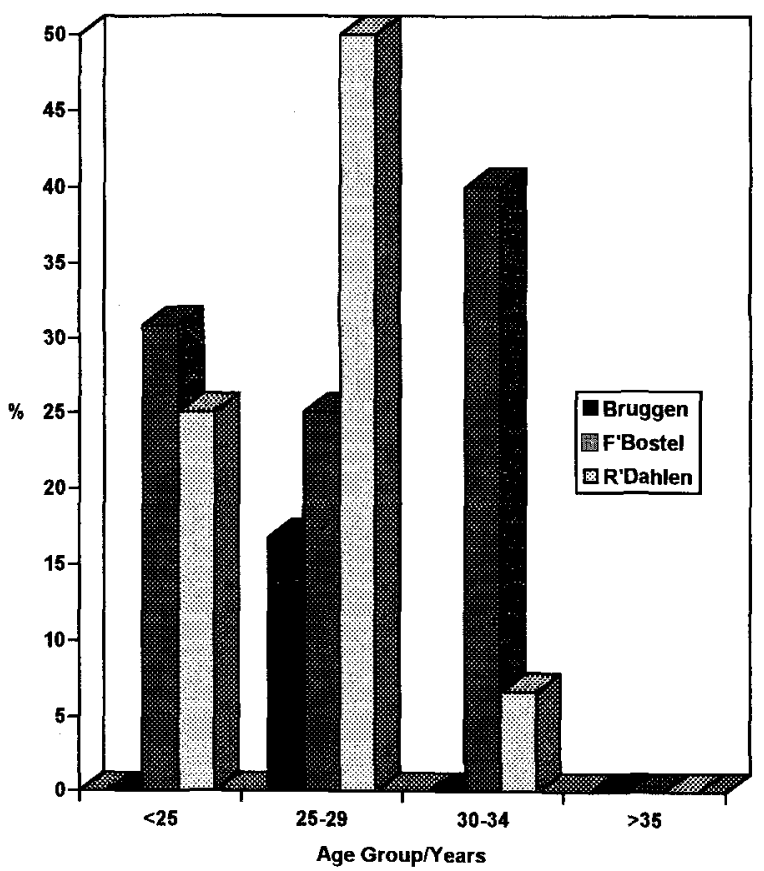

Fig 3. Comparison of Paternal Smoking Distribution, by Age, in Bruggen, Fallingbostel and Rheindahlen of New-born Babies, January - June 1996.

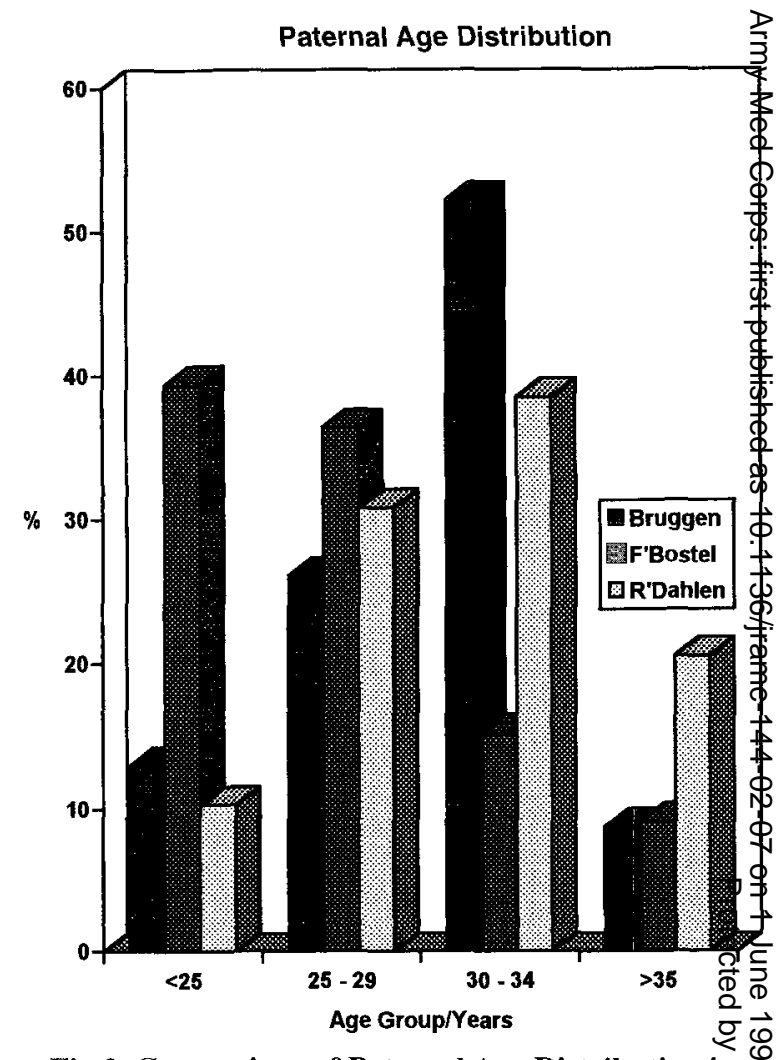

Fig 2. Comparison of Paternal Age Distribution ig 9

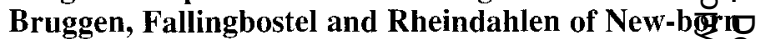

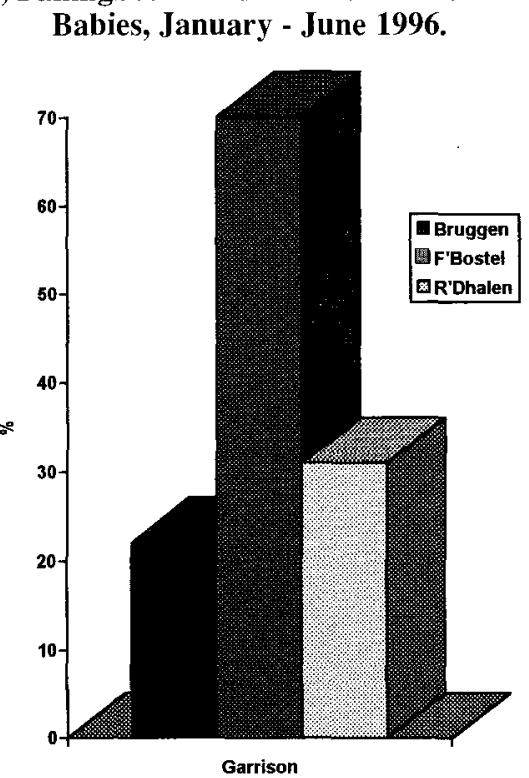

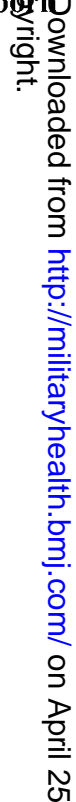

Fig 4. Paternal Absence of Greater than One Month

During the Confinement Period in Bruggen,

Fallingbostel and Rheindahlen, of New-born Babies, January - June 1996. 
The socially disadvantaged are less likely to attend routine health checks and thus obtain "routine" health promotion and education. The current Minister for Public Health is convinced that the issue of "inequalities of health" is important. It is believed that the way forward in addressing this problem is to build an active partnership with clients so that a sense of community is established that will ultimately empower all concerned. In Armed Forces communities it would appear important to concentrate on areas of relative poverty, such as Fallingbostel in this study and target health promotion at those populations.

A major factor that can no longer be ignored if we are to improve the health of our Service personnel and their families is smoking, which is still unacceptably high amongst fathers in the Army (Fig 3). Although antismoking campaigns increase awareness they have little impact on the prevalence (14). However parents, irrespective of social class, are receptive to intervention in their lifestyle habits when the issues are relevant to their current situation or problem (15). Providing emotional support and targeting anti-smoking education at parents in the antenatal period and immediately after the birth of a child may well result in parents quitting smoking for good and therefore result in less morbidity from respiratory disease for their children. A reduction in respiratory disease in infancy may even further decrease the rate of sudden infant death syndrome (SIDS).

This study also highlighted not only the absence of paternal support during pregnancy (Fig 4) but also the correlation that paternal absence appears to have with social characteristics and in particular rank in the Armed Forces. The importance of a father's absence may well result in social isolation for the mother with resultant psychological effects which may cause emotional problems in her children and affect many aspects of their health and behaviour in adult life. Signing up to the European Social Chapter, and therefore resultant legislation, may result in clarification of paternity leave and so improve paternal support, thus reducing social isolation for Service mothers.

Health visitors have a diverse and varied role (11) but one of their major roles is health promotion and education to families with new-born children. It is clear that health visitors are best placed to provide the support that socially disadvantaged families require. A child in the lowest social class is twice as likely to die before the age of 15 years as a child in the highest social class (16). Furthermore the social class gap in deaths in children from accidents has widened over the past decade (17) but interventions by health education, particularly by health visitors can significantly decrease the incidence of childhood injury (10). In addition health visitors may be best placed to tackle the problems relating to paternal smoking (18). Studies looking at health visitor workload in Britain have revealed that families with identified needs have twice as many contacts with the health visiting service than for other families. This study demonstrates that there is a difference in need based on social characteristics and health visitor workload, with a greater need for those more socially disadvantaged such as the families in Fallingbostel.

Members of the Armed Forces and their dependants should not be considered to be "classless" and based on their social characteristics it would be possible to allocate a social class group. Therefore one can expect that with the differences in social class groups within the Armed Forces there will be "inequalities in health" present. If one is going to narrow the gap resulting from "inequalities in health" and rebuild a sense of community within Service families then one should consider allocating appropriate resources to the poorer areas to support and encourage o parents in the task of ensuring that all children reach $\overrightarrow{0}$ adulthood with their health uncompromised. Garrisons $\overrightarrow{\vec{H}}$ where mothers are younger, less educated, more likely to $\vec{\omega}$ smoke, more likely to bottle feed and to suffer greater separation from their spouses during pregnancy should be targeted, with health visitors playing the lead role in providing health promotion and education. Evaluation of interventions such as the child development programme in Bristol (17) which utilises mature mothers to provide support to younger mothers has shown positive benefits. In the Armed Forces community such empowerment? through health promotion and education by health visitor $\bar{E}-$ although initially requiring an increase in resources fo those areas that need to be targeted may at a later date lead to more mature mothers within units providing support 8 younger mothers and therefore a reduction in resources thus achieving the aim of an empowered and healthg community.

\section{Acknowledgments}

The authors are grateful to all the health visitors that helped to administer the questionnaires.

\section{REFERENCES}

1. Newhouse SM. The Colchester Army children's study; summary report. Colchester Community Paediatric Department; 1994.

2. KeRshaw CR, InCENT SH. Care of Service children in the Gosport Peninsula. J R Nav Med Serv 1981; 67: 117-124.

3. Holroyd SJ, Madeley RJ, Parson JC. Post neonatal mortality in the Nottingham Health District. Community Med 1989; 11(4): 342-351.

4. Holland WW, Detels R, Knox G. Oxford Textbook of Public Health. Second Edition. Oxford University Press, 1991.

5. CLARK JY, THOMPSON IM. Military rank as a measure $\frac{0}{2}$ of socioeconomic status and survival from prostate $\frac{D}{0}$ cancer. South Med J 1994; 87(11): 1141-1144.

6. FEIN O. Influence of social class on health status: N American and British research on health inequalities. $N$ J Gen Intern Med 1995; 10(10): 577-586.

7. Ostherg V. Social class differences in child mortality. $J$ Epidemiol Community Health 1992; 46(5): 480-484. 
8. Department of Health. The Health of the Nation. HMSO, London 1992.

9. Tannahill A. What is health promotion? Health Educ $J$ 1985; 44: 167-168.

10. RoberTs I, KRAMER MS, SuISSA S. Does home visiting prevent childhood injury? A systematic review of randomised controlled trials. Br Med J 1996; 312: 2933.

11. Symonds A. Health visiting: past and future. A power of good: health visiting in the 1990s. London; College Hill Press, 1994.

12. Miller SA StJ. Report on the British Forces cot death prevention study. Department of Preventive Medicine, Royal Army Medical College, July 1995.

13. MANn SL, Wadsworth ME, Colley JR. Accumulation of factors influencing respiratory illness in members of a national cohort and their offspring. $J \frac{D}{3}$ Epidemiol Community Health 1992: 46(3): 286-292.

14. CAmpion P, Owen L, MCNeILl A, MCGuire C. 3 Evaluation of a mass media campaign on smoking and $\stackrel{\mathbb{Q}}{\Omega}$

pregnancy. Addiction 1994; 89(10): 1245-1254.
15. STotT NC, PILl RM. "Advise yes, dictate no."응 Patients' views on health promotion in the consultation. Fam Pract 1990; 7(2): 125-131.

16. Woodroffe C, Glickman M, Barker M, Power C. Children, teenagers and health: the key data. Buckingham: Open University Press, 1993.

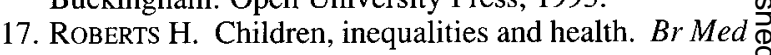
$J$ 1997; 314: 1122-1125.

18. Chalmers KI. Working with men: an analysis of health visiting practice in families with young $\vec{\circ}$ children. Int J Nurs Stud 1992; 29(1): 3-16. 